\title{
Transmission of visceral leishmaniasis in dogs in a risk area of the metropolitan region of Belo Horizonte, Minas Gerais, Brazil
}

[Transmissão da leishmaniose visceral em cães em área de risco da Região Metropolitana de Belo Horizonte, Minas Gerais, Brasil]

\author{
E.G.P. Lopes ${ }^{1,2}$, M.E. Oviedo-Pastrana ${ }^{1}$, L.F.N.M. Borges ${ }^{1,3}$, A.C.P. Freitas ${ }^{1}$, E.S. Dias ${ }^{4}$, S.R. Silva ${ }^{4}$, \\ J.P.A. Haddad ${ }^{1}$, J.C. França-Silva ${ }^{5}$, D.F.M. Soares ${ }^{1}$ \\ ${ }^{1}$ Escola de Veterinária - Universidade Federal de Minas Gerais - Belo Horizonte, MG \\ ${ }^{2}$ Secretaria Municipal de Saúde - Prefeitura de Belo Horizonte, MG \\ ${ }^{3}$ Serviço de Controle de Zoonoses - Secretaria Municipal de Saúde - Prefeitura de Juatuba, MG \\ ${ }^{4}$ Centro de Pesquisas René Rachou - Belo Horizonte, MG \\ ${ }^{5}$ Instituto de Ciências Biológicas - Universidade Federal de Minas Gerais - Belo Horizonte, MG
}

\begin{abstract}
Visceral leishmaniasis (VL) has spread rapidly across cities in the metropolitan region of Belo Horizonte. The aim of this study was to investigate VL dynamics in a prospective cohort study of dogs in Juatuba, between 2010 and 2011, to confirm the incidence of Leishmania infantum, and to assess possible risk factors associated with infection. An observational and prospective closed cohort study was performed using serology testing in dogs, randomly selected from the whole municipality. All seronegative dogs, or dogs with inconclusive results were monitored using indirect immunofluorescence (IIF) at 6-month intervals. The dog's owners completed a semi-structured questionnaire to assess possible causal factors of seroconversion, and the responses were assessed using logistic regression. The canine incidence coefficient was 206/1,000 dogs per year (CI: 178-238), and a cluster was identified in an area with a high concentration of seropositive dogs, but a low overall canine population. Large dogs were identified as a risk factor and the following variables were identified as protection factors: dogs aged over 4 years, daily peridomicile cleaning, and better socioeconomic conditions. VL is spreading over a large area in Juatuba in a short period of time.
\end{abstract}

Key words: leishmaniasis, incidence, seroconversion, risk factors, cluster

\section{RESUMO}

A leishmaniose visceral ( $L V$ ) expandiu-se de forma rápida e extensa pelos municípios da Região Metropolitana de Belo Horizonte. Objetivou-se estudar a dinâmica da LV em uma coorte prospectiva de cães em Juatuba, entre 2010 e 2011, para verificar a incidência e fatores de risco associados à infecção por Leishmania infantum. Foi feito um estudo observacional e prospectivo de coorte fechada por meio de análise sorológica em cães selecionados aleatoriamente em todo o município, com acompanhamento semestral dos resultados soronegativos e indeterminados na imunofluorescência indireta (IFI). Usou-se questionário semiestruturado junto aos proprietários de cães para avaliação da soroconversão e dos fatores determinantes a essa, por meio da regressão logística. O coeficiente de incidência canina foi de 206/1000 cães.ano (IC: 178 - 238), e foi identificado cluster em área com elevada concentração de cães soropositivos, mas com baixa densidade populacional canina. A variável cão de porte grande foi identificada como fator de risco, e as variáveis idade do cão superior a quatro anos, limpeza diária do peridomicílio e melhores condições socioeconômicas como fatores de proteção. A infecção por LV está ocorrendo em curto período de tempo e com ampla distribuição em Juatuba.

Palavras-chave: leishmaniose, incidência, soroconversão, fatores de risco, cluster

Recebido em 24 de novembro de 2015

Aceito em 28 de julho de 2016

E-mail: elianegplopes@gmail.com 


\section{INTRODUCTION}

Visceral leishmaniasis (VL) or kala-azar is a zoonosis. It is one of the main endemic diseases with a global public health concern and is present in most developing countries, such as Brazil (Health..., 2013). VL results in death if not treated, the majority of leishmaniasis deaths go unrecognized, and even with treatment access, VL may result in case-fatality rates of $10-20 \%$ (Alvar et al., 2012). This disease is caused by the agent Leishmania infantum (Romero and Boelart, 2010), and is transmitted through a vector. The primary vector in Brazil is the phlebotomine species Lutzomyia longipalpis (Lutz and Neiva, 1912), which is found around and inside the houses (Dias et al., 2011). Dogs are considered to be the main domestic reservoir and the main source of infection for phlebotomines in urban areas. The canine host is an important link in the transmission cycle (Manual..., 2014).

Dogs can present a wide range of clinical symptoms of VL, but most infected dogs remain asymptomatic (Barata et al., 2013). Animals can be infected for a long time without being serologically positive and spontaneous remission has been seen in a seropositive minority. Seroconversion occurs in seronegative dogs as well as in dogs with inconclusive results, turning into positive animals; and this shows the importance of serological surveys for early diagnosis of infection in dogs (Lopes et al., 2010). Identifying risk factors for seroconversion in dogs is crucial for developing adequate strategies for VL prevention and control (CouraVital et al., 2013; Borges et al., 2014).

Several socioeconomic factors inherent in large cities have contributed to the urbanization of VL, which are present in five regions of Brazil (Leishmaniose..., 2013). The risk of human visceral leishmaniasis (HVL) varies according to social integration, the number of dogs in the household, and the environmental and living conditions (Borges et al., 2009). Studies have shown that infection in dogs precedes infection in humans (Oliveira et al., 2001). Juatuba had the index case of the disease in 1999, with six cases recorded until 2013. A canine positivity rate of around $20 \%$ was registered in samples of spontaneous requests made by the population. The municipality does not have enough structure to carry canine serological inquiry for VL. The epidemiological analysis will help verify the prevention and control measures that need to be adopted. A cohort study allows the long-term monitoring of a canine population through specific analyses of prospective study data (Barboza et al., 2006; Coura-Vital et al., 2013). Early detection of seroconversion in dogs, with consequent decrease of canine incidence is necessary because infected dogs play an essential role in VL transmission to humans in urban areas (Werneck, 2014).

The aim of the current study was to investigate the transmission dynamics of VL in a prospective cohort study of dogs in Juatuba, between 2010 and 2011, to verify the incidence and risk factors associated with infection by Leishmania infantum.

\section{MATERIALS AND METHODS}

The study was approved by the Research Ethics Committee (COEP- $\mathrm{n}^{\circ}$ 0325.0.203.000-10) and the Animal Research Ethics Committee (CETEA-n $^{\circ}$ 170/2010), both from the Universidade Federal de Minas Gerais (UFMG). The owners signed the terms of consent for research before blood sample collection from their dogs and completion of the questionnaire.

Between 2010 and 2011 a prospective observational closed cohort epidemiological study was performed in the municipality of Juatuba, Minas Gerais; blood samples were collected from dogs at a six-month interval. Juatuba is located within the metropolitan region of Belo Horizonte (capital of Minas Gerais) and has an estimated human population of 22,221 inhabitants (Minas..., 2013) and a canine population of 5,316 dogs, as reported by the local service for the Control of Zoonoses.

Data were collected on three occasions to determine the prevalence, incidence, and risk factors for VL. For the serological diagnosis, an ELISA assay (commercial kit, ELISA $/ \mathrm{S}^{\circledR}$ ) and an indirect immunofluorescence (IIF) from BioManguinhos/FIOCRUZ kit were used. The negative, positive, or inconclusive results were defined by IIF and dogs were considered positive for VL when they presented reagent dilutions $\geq 1: 40$. The first set of data allowed the dogs to be identified and the prevalence study to be developed (Borges et al., 2014). The animals randomly selected in this initial phase of work 
were mostly: male (54.3\%), aged up to four years $(69.5 \%)$, short-haired $(77.6 \%)$, medium to large size $(70.2 \%)$ and mixed breed $(75.2 \%)$. The second set of data were collected six months later from animals that were seronegative or from animals with inconclusive results during the first data collection. The third set of data was collected in the subsequent semester from animals that were still serologically negative and from animals with inconclusive results.

Calculation of the effects of the total period of study was done by the formula (Pereira, 2002):

Incidence $=$ number of new cases of the 2 nd and 3 rd collections $\mathrm{x} 100$

$(0.5$ years $*$ number of samples in the 2 nd collection $)+(1$ year $*$ number of samples in the $3 \mathrm{rd}$ collection)

During the study, the owners of the animals answered to questions about demographic, socioeconomic, and behavioral factors, as well as questions regarding their knowledge about the disease, including transmission, vectors, reservoirs, and prevention and control measures. A logistical regression model was used to find an association between the presence of the disease and the causal factors obtained from the questionnaires. The time variable was included in the analysis of the three groups representing the three sampling times as a fixed effect in all models, to maintain its influence during the study. The odds ratio (OR) was used because LV is a common disease with prevalence and incidence known whose values would not diverge the relative risk (RR), as discussed by Lima-Costa and Matos (2006). For the statistical analysis, the software Stata $12\left(\operatorname{StataCorp}^{\circledR}\right)$ was used.

The human and canine cases were georeferenced and imported into a geographic information system using the software ArcGis 9.3 (ESRI, USA). Spatial and spatio-temporal analyses were carried out. The Kernel density was used to identify dense areas in the canine population, disease cases, and positivity rates (Klooga et al., 2009) in dogs. The local (Local Moran Index) and global spatial autocorrelation (Moran I) were applied to assess the randomness of the data and to identify and analyze clusters and uncharacteristic values (Pfeiffer et al., 2009). For the spatio-temporal analysis, the scan statistics were used with the Poisson distribution, using the software SatScan 9.2.

\section{RESULTS}

The first set of data (Borges et al., 2014) assessed the presence of VL in 957 dogs. A total of 102 were seropositive and were euthanized, 805 were seronegative and 50 dogs had inconclusive results; the prevalence was $10.6 \%$ (95\% CI: 10.07-11.13). The second set of data involved the remaining 855 animals; blood samples were collected from 595 of the dogs (sample loss of $30.4 \%$ ), of which 123 dogs had become seropositive and were euthanized. The third data set consisted of the remaining 472 dogs; samples were collected from 433 dogs (sample loss of $8.3 \%$ ) and 28 had become seropositive (Table 1).

Table 1. Distribution of the serological results from dogs in the municipality of Juatuba, from 2010 to 2011

\begin{tabular}{lccc}
\hline & $\begin{array}{c}\text { First data set } \\
\text { (Borges } \text { et al., 2014) }\end{array}$ & Second data set & Third data set \\
\hline $\mathrm{N}$ & 957 & 595 & 433 \\
Seropositive & 102 & 123 & 28 \\
Seronegative & 805 & 415 & 364 \\
Undetermined & 50 & 57 & 41 \\
Sample Loss & ----- & 260 & 39 \\
Prevalence & $10.70 \%$ & ----- & ---- \\
Incidence & ----- & $207 / 1,000$ dogs & $65 / 1,000$ dogs \\
\hline
\end{tabular}


Throughout the whole study period, there was a sample loss (299 dogs) and the main reasons were: natural death or violence against the dog's life $(34.2 \%)$, absence $(30.6 \%)$, refusal by owner $(13.2 \%)$, and others $(22.1 \%)$ represented by closed house, address not found, and the presence an adult at the time of the visit. In the second semester of the study, the incidence was 207 cases per 1,000 dogs (CI: 175-242) and in the third semester the incidence was 65 cases per 1,000 dogs (CI: 43-92). Over the total study period, the incidence coefficient was 206/1,000 dogs per year (CI: 178-238).

From the variables studied to characterize the profile of the owner, of the environment, and of the dog, 38 were pre-selected for the univariate analysis with a significance level of $P \leq 0.20$. Of these variables, 18 were defined as protection factors (Table 2) and 20 as risk factors (Table 3) for canine visceral leishmaniasis (CVL) infection. The variables were organized in the two tables below in descending order of statistical significance.

Ten of the variables representing protection factors for CVL (Table 2) had a p- value $<0.05$ and were associated with: an older dog (living with the dog for over 3 or 5 years, dog above 4 years old), improved socioeconomic factors (sewerage and water treatment services, increase in income), knowledge of disease history in dogs (death of dog in less than 1 year and known cause of death), and general prevention methods (administration of rabies vaccine and peridomicile cleaning). Even with a low statistical significance, the remaining variables also indicate clear unfavorable conditions for CVL: associated with the dog (long-haired animal, dog originally from the city), decrease in organic material (garbage collection service two or four times a week), and building characteristics (living in apartment, internal, and external plastering).

Table 2. Variables pre-selected by the univariate statistical analysis defined as protection factors against visceral leishmaniasis in dogs

\begin{tabular}{lcccc}
\hline Variable & $\begin{array}{c}\text { Odds Ratio } \\
\text { (OR) }\end{array}$ & p-value & $\begin{array}{c}\text { Confidence Interval } \\
(95 \%)\end{array}$ \\
\hline Living with the dog for over 5 years & 0.507 & 0.00 & 0.353 & 0.727 \\
Dogs over 4 years of age & 0.540 & 0.00 & 0.392 & 0.744 \\
Sewage service & 0.642 & 0.00 & 0.480 & 0.858 \\
Living with the dog for over 3 years & 0.650 & 0.00 & 0.490 & 0.861 \\
Treated water service & 0.563 & 0.01 & 0.373 & 0.852 \\
Known cause of dog's death & 0.608 & 0.01 & 0.422 & 0.876 \\
Increase in income & 0.704 & 0.02 & 0.529 & 0.936 \\
Peridomicile cleaning & 0.662 & 0.02 & 0.468 & 0.937 \\
Death of dog in less than 1 year & 0.669 & 0.03 & 0.464 & 0.966 \\
Rabies vaccination given & 0.628 & 0.04 & 0.405 & 0.974 \\
Long-haired animal & 0.719 & 0.06 & 0.509 & 1.015 \\
Living in an apartment & 0.754 & 0.09 & 0.546 & 1.043 \\
Garbage collection 2x/week & 0.749 & 0.09 & 0.534 & 1.050 \\
Plastered interior of home & 0.687 & 0.10 & 0.439 & 1.075 \\
Feeding dog with household food & 0.602 & 0.11 & 0.322 & 1.126 \\
Plastered exterior of home & 0.822 & 0.18 & 0.617 & 1.094 \\
Garbage collection 4x/week & 0.612 & 0.18 & 0.296 & 1.264 \\
Dog originally from Juatuba & 0.814 & 0.19 & 0.597 & 1.109 \\
\hline
\end{tabular}


Table 3. Variables pre-selected by univariate statistical analysis defined as a risk for visceral leishmaniasis in dogs

\begin{tabular}{|c|c|c|c|c|}
\hline \multirow{2}{*}{$\begin{array}{l}\text { Variable } \\
\text { Previous VL exam }\end{array}$} & \multirow{2}{*}{$\begin{array}{c}\begin{array}{c}\text { Odds Ratio } \\
(\text { OR })\end{array} \\
2.713\end{array}$} & \multirow{2}{*}{$\frac{\mathrm{p} \text {-value }}{0.00}$} & \multicolumn{2}{|c|}{$\begin{array}{c}\text { Confidence Interval } \\
(95 \%)\end{array}$} \\
\hline & & & 1.396 & 5.273 \\
\hline Large dog & 1.672 & 0.01 & 1.170 & 2.389 \\
\hline Proximity to livestock & 1.478 & 0.01 & 1.115 & 1.960 \\
\hline Proximity to trees & 1.600 & 0.01 & 1.102 & 2.325 \\
\hline Birds and/or mammals in the building & 1.496 & 0.02 & 1.069 & 2.094 \\
\hline Contact with other dogs in the area & 1.641 & 0.02 & 1.082 & 2.489 \\
\hline Medium-sized dog & 1.444 & 0.03 & 1.030 & 2.024 \\
\hline Proximity to forest & 1.322 & 0.06 & 0.995 & 1.758 \\
\hline Soil surrounding the dwelling & 1.862 & 0.08 & 0.931 & 3.724 \\
\hline Animal remains in kennel at night & 1.292 & 0.09 & 0.957 & 1.746 \\
\hline Vaccine given against CVL & 3.116 & 0.11 & 0.785 & 12.365 \\
\hline Daily use of insecticide & 4.496 & 0.11 & 0.718 & 28.141 \\
\hline Mixed color of dog & 1.401 & 0.11 & 0.928 & 2.116 \\
\hline Other dogs entering home & 1.284 & 0.12 & 0.934 & 1.764 \\
\hline Use of repellant collar & 2.144 & 0.15 & 0.753 & 6.106 \\
\hline Proximity to poultry breeding & 1.235 & 0.16 & 0.919 & 1.659 \\
\hline Cement and soil surrounding dwelling & 1.618 & 0.17 & 0.820 & 3.193 \\
\hline More than 4 dogs at home & 1.271 & 0.17 & 0.901 & 1.795 \\
\hline Presence of garbage & 1.212 & 0.17 & 0.920 & 1.597 \\
\hline Presence of organic material & 1.212 & 0.19 & 0.907 & 1.619 \\
\hline
\end{tabular}

Seven of the variables representing risk factors for CVL (Table 3) had a p-value $<0.05$, with one of these being associated with the presence of the disease (previous CVL exam), some associated with the size of the dog (medium and large dogs), and others with the proximity to animals and trees (contact with other dogs in the neighborhood, birds and/or mammals in the building, proximity to livestock and trees).

There were 13 variables with a low statistical significance representing a risk for CVL, and 5 of these were related to the contact with other animals and risk environments (animal staying in kennel at night, more than 4 dogs in the household, proximity to the forest, the entry of other dogs into the house, proximity to poultry). Four other variables represented favorable environment and conditions to the vector (presence of organic material, presence of garbage, dwelling surrounded by soil and cement), and another facilitated the camouflage of the vector (mixed colored dog). The use of a repellent collar, daily use of an insecticide, and vaccination against VL were variables that theoretically should be protection factors, but instead were characterized as risk factors, most likely due to the low frequency, making the detection of an association difficult.

Different interactions were tested with preselected variables resulting in three preliminary models. The presence of sewage and water treatment systems and a household income above minimum wage were independently found to be protection factors against $\mathrm{CVL}$ on the three preliminary models. Each of these three variables were tested with the age of dog, size of dog, peridomicile cleaning, and sampling time. However, when all three were united in a single model, they lost statistical significance due to the interactions between them.

A new variable called SWI was created, by integrating the presence of sewage and water treatment network, and household income above minimum wage. The variable SWI combined the main socioeconomic conditions assessed in the study. Four categories were created: absence of all three conditions (0), presence of one 
condition (1), presence of two conditions (2), and presence of all three conditions (3). The final model was created from the integration of the variables: SWI, age of dog, size of dog, daily peridomicile cleaning, and sampling time (Tab. 4). The final model was assessed and deemed appropriate following the Hosmer-Lemeshow test, which revealed a chi-square value of 12.26 and a p-value equal to 0.139 .

The Kernel density maps (Figure 1) identified areas of dense canine population (A), cases of CVL (B), and CVL positivity rate (C).

In general, the areas with the highest canine density coincided with the areas with the highest number of CVL cases and highest positivity rates. Therefore, the area defined by the circle represents a low canine density, a high number of cases, and a high positivity rate for CVL. In this figure, the human cases are marked with their respective years of notification.

The overall spatial autocorrelation for the canine population (Index $=0.66 ; \mathrm{P}<0.001$ ) and the positivity rate (Index $=0.24 ; \mathrm{P}=0.01$ ) indicates that the data were not randomly distributed. The local indicator of spatial association (LISA) identified statistically significant clusters in the canine population and disease positivity rates. Interpreting the location of clusters was facilitated by census sectors of the municipality (Figure 2).

A large cluster of type LL (low canine population with low vicinity) was located in the west of Juatuba (Figure 2A) and was associated with another cluster with a high positivity rate of type $\mathrm{HH}$ (high positivity rate with high vicinity), which is represented in Figure 2B. The spatiotemporal analysis using the Poisson distribution revealed an association between the $253 \mathrm{VL}$ seropositive dogs, the canine population in each location and the time variable in months. A primary cluster was identified in the coordinates $\mathrm{X}=572302 \mathrm{Y}=7791350$, with a diameter of $1.276 \mathrm{~m}$, a relative risk of 11 times and a p-value $<0.001$ (Fig. 2B). This cluster confirmed the relevance of the area already identified in the previous spatial analyses.

Table 4. Final logistical regression model for canine visceral leishmaniasis in the municipality of Juatuba, from 2010 to 2011

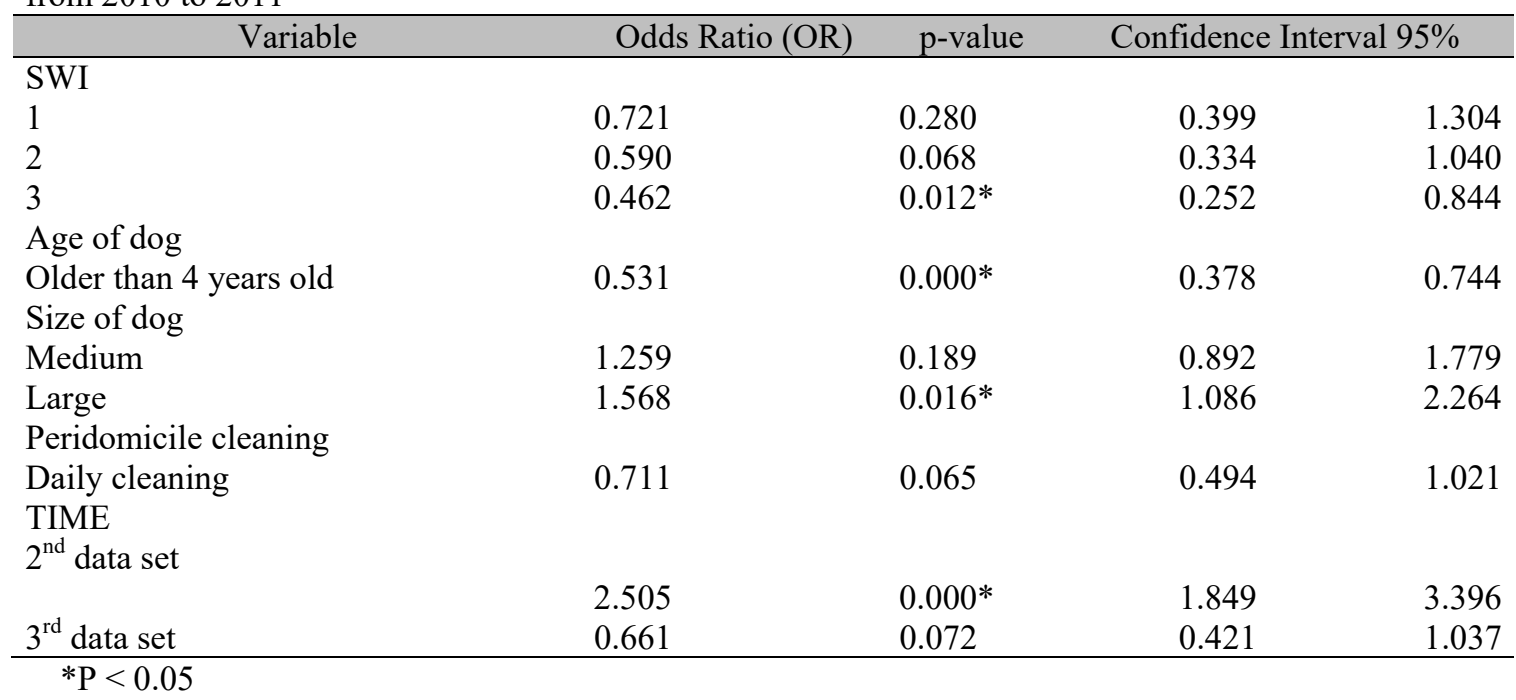




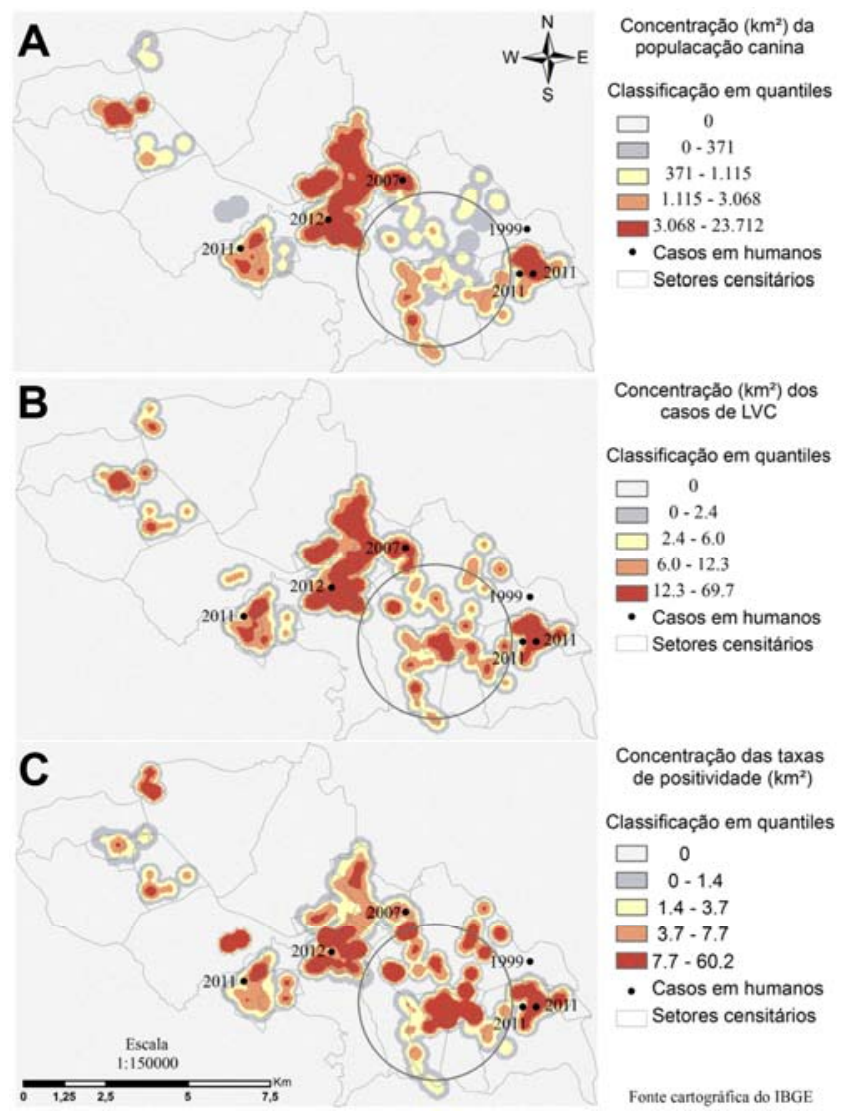

Figure 1. Estimate of densities using the Kernel method, for the canine population (A), positive canine cases (B), and positivity rate (C) of visceral leishmaniasis in dogs from Juatuba, 2010 and 2011.
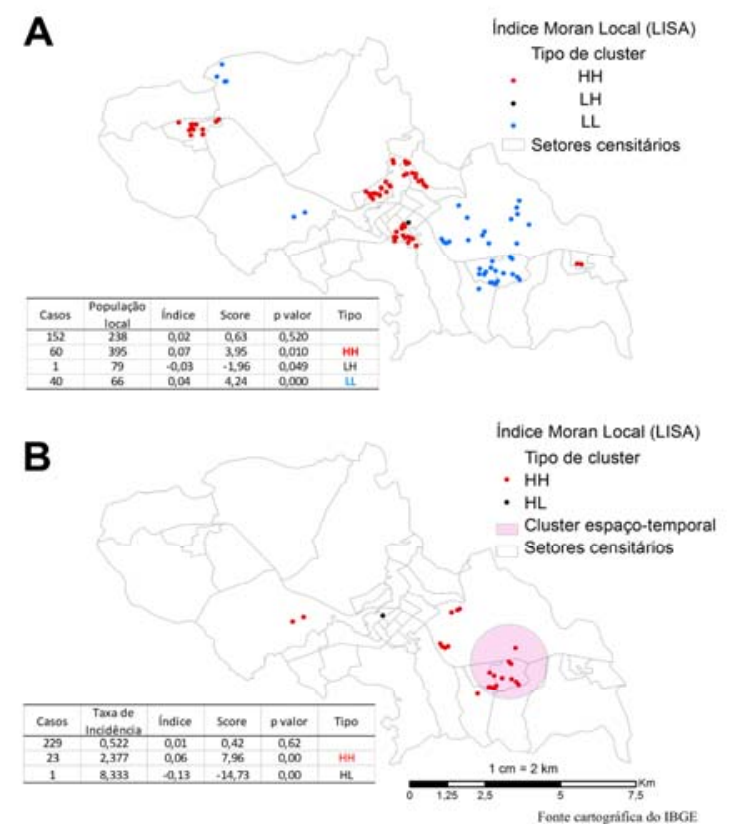

Figure 2. Local Moran Index (LISA), cluster analysis, and unconventional values for the canine population (A) and for the positivity rate in dogs (B), Juatuba, 2010 to 2011. 


\section{DISCUSSION}

Juatuba is considered to be a city with sporadic VL transmission, as classified by the Ministry of Health (Manual..., 2014); however, the high values of annual prevalence and the incidence coefficients showed the interaction between the causal factors in a short period of time. A similar result was observed in the metropolitan region of Salvador (Barboza et al., 2006) and in Belo Horizonte, considered a city with high transmission rates (Coura-Vital et al., 2013). Also, infection in dogs was confirmed to precede the disease in humans (Oliveira et al., 2001) and this is the problem of under-reporting cases (Desjeux, 2004). Six human cases of VL were recorded in Juatuba between 1999 and 2013.

The frequency of seroconversion in dogs in the second phase of the study $(123 / 595=20.7 \%)$ was pronounced. It is possible that the time spent removing seropositive dogs from the first data set contributed to this, due to difficulties in human resources and municipal logistics, and the lack of experience in sampling surveys or previous censuses. Several authors stated that time and the partial withdrawal of dogs for euthanasia, as well as discontinuing control measures, were the main reasons for a low effectiveness of the program (Lopes et al., 2010; Barata et al., 2013).

The municipality present certain homogeneity favorable for the occurrence of VL making the risk and protection factors difficult to identify. This explains the few associations with canine positivity in the multivariate analysis. The variable SWI was expressed as a protection factor against CVL in the presence of one, two, or three key socioeconomic conditions (sewage network, treated water, and household income above minimum wage). Only category three (3) was statistically significant $(\mathrm{p}$-value $=0.012)$, implying that the dog was 2.2 (1/OR 1/0.462) times more likely to be protected when compared to other dogs living with owners in poor socioeconomic conditions. This result is consistent with studies performed by Borges et al. (2009) and Belo et al. (2013), who found an association between $L$. infantum infection and the presence of dogs in poor socioeconomic conditions.
Dogs older than four years were 1.9 (1/OR 1/0.531) times more likely to be protected against VL compared to younger dogs; the pvalue was $<0.001$. Silva et al. (2001) explained that this protection is due to the increase in immunity with age. Rondon et al. (2008) also described a significant difference for the occurrence of VL in dogs aged between 1 and 6 years. However, França-Silva et al. (2003) and Barboza et al. (2006) did not observe an association between age and seropositivity for VL.

Large dogs were 1.56 times more likely to become infected when compared to smaller dogs; the p-value was 0.016. Other authors have already found an association between the presence of CVL and larger dogs (Coura-Vital et al., 2013).

Organic matter is a food source for the larvae of the female vector. The presence of garbage, dry leaves and conditions of poor peridomicile hygiene were also associated with CVL, with seroconversion being approximately 3 times more likely (Coura-Vital et al., 2013). In the current study, daily peridomicile cleaning resulted in protection against leishmaniasis, with the animal being 1.4 (1/OR 1/0.711) times more likely to be protected compared to less frequent cleaning. According to Barata et al. (2013), human cases of VL in Governador Valadares occurred in poor living conditions, basic sanitation, and garbage collection, as well as the accumulation of organic matter and the presence of other animals.

The municipality of Juatuba has areas with rural characteristics and the presence of large areas of vegetation (Lopes, 2013). Borges et al. (2014) identified a cluster of seropositive dogs in the most urbanized region of Juatuba (city center) with the risk of infection increasing by 2.80 times $(p<0.001)$. In the current study, the area identified in the cluster from the spatio-temporal analysis (Fig. 2B) was characterized as the area of recent urban expansion with large environmental changes and an increased risk of infection by 11.1 times $(p<0.001)$. It has uneven terrain, unpaved streets, and municipal sanitary landfill sites. More detailed analyses of this area have revealed areas of poor housing conditions, a population with a low level of education and purchasing power, a lack of basic sanitation, and 
cohabitation with animals. Health education activities should be intensified in the population to increase knowledge of $\mathrm{LV}$ and cooperation in preventing and controlling the disease.

The urbanization of CVL is still a serious public health problem in many parts of Brazil (FrançaSilva et al., 2003; Morais et al., 2008; Prado et al., 2011; Dias et al., 2011; Barata et al., 2013). In Juatuba, CVL is highly dynamic and widely distributed throughout the municipality (Fig. 1B); urbanization of new areas increases the risk of VL in the animals, and possibly, in humans. Human cases of VL have not been identified in the cluster area, but the possibility of VL emerging must be considered as CVL precedes the disease in humans. The epidemiological panorama of VL reveals the vulnerability of Juatuba due to the favorable characteristics presented in this city for the maintenance and spread of the disease.

The way in which urban space is occupied influences the likelihood of VL occurring in humans and dogs (Lopes et al., 2010). Spatial analysis guides the allocation of resources for environmental intervention and other actions involving different sectors (Morais et al., 2008; Prado et al., 2011). The non-static behavior of the disease requires permanent monitoring combined with increasingly detailed statistical, spatial, and temporal analyses.

\section{CONCLUSIONS}

The population interviewed was characterized by unfavorable socioeconomic conditions, low rate of education, little knowledge of the LV, and confounding with other diseases, reflecting the absence of prevention and control of the disease by most dog owners. Large dogs were identified as a risk factor and the following variables were identified as protection factors: dogs aged over 4 years, daily peridomicile cleaning, and better socioeconomic conditions. Juatuba has favorable environmental conditions for the maintenance of VL predominantly outside the house and surroundings with abundant presence of vegetation, organic matter, diversity of animals, and basic sanitation deficiency. The high incidence value shows that VL is spreading over a large area in Juatuba in a short period of time. The area identified as high risk requires immediate intervention by the local authorities, because it may precede disease in humans.

\section{REFERENCES}

ALVAR, J.; VÉLEZ, I.D.; BERN, C. et al. Leishmaniasis worldwide and global estimates of its incidence. Plos one, v.7, p.1-12, 2012.

BARATA, R.A.; PEIXOTO, J.C.; TANURE, A. et al. Epidemiology of visceral leishmaniasis in a reemerging focus of intense transmission in Minas Gerais state, Brazil. Rev. BioMed Res. Int., v.2013, p.1-6, 2013.

BARBOZA, D.C.P.M.; GOMES NETO, C.M.B.; LEAL, D.C. et al. Estudo de coorte em áreas de risco para leishmaniose visceral canina, em municípios da região metropolitana de Salvador, Bahia, Brasil. Rev. Bras. Saúde Prod. Anim., v.7, p.152-163, 2006.

BELO, V.S.; WERNECK, G.L.; BARBOSA, D.S. et al. Factors associated with visceral leishmaniasis in the Americas: a systematic review and meta-analysis. PLOS Neglected Trop. Dis., v.7, p.1-12, 2013.

BORGES, B.K.A.; SILVA, J.A.; HADDAD, J.P.A. et al. Presença de animais associada ao risco de transmissão da leishmaniose visceral em humanos em Belo Horizonte, Minas Gerais. Arq. Bras. Med. Vet. Zootec., v.61, p.1035-1043, 2009.

BORGES, L.F.N.M.; LOPES, E.G.P.; FREITAS, A.C.P. et al. Prevalência e distribuição espacial da leishmaniose visceral em cães do município de Juatuba, Minas Gerais, Brasil. Ciênc. Rural, v.44, p.352-357, 2014.

COURA-VITAL, W.; REIS, A.B.; FAUSTO, M.A. Risk factors for seroconversion by Leishmania infantum in a cohort of dogs from an endemic area of Brazil. Plos One, v.8, p.1-9, 2013.

DESJEUX, P. Leishmaniasis: current situation and new perspectives. Comp. Immun. Microbiol. Infect. Dis., v.27, p.305-318, 2004.

DIAS, S.E.; SILVA, R.S.; FRANÇA, J.C.S. et al. Eco-epidemiology of visceral leishmaniasis in the urban area of Paracatu, state of Minas Gerais, Brazil. Vet. Parasitol., v.176, p.101-111, 2011. 
FRANÇA, J.C.S.; COSTA, R.T.; SIQUEIRA, A.M. et al. Epidemiology of canine visceral leishmaniasis in the endemic area of Montes Claros municipality, Minas Gerais state, Brazil. Vet. Parasitol., v.111, p.161-173, 2003.

HEALTH topics leishmaniasis, [s.l.]: WHO, 2013. Available in: <http://www.who.int/ topics/leishmaniasis/en/>. Accessed in: 21 Oct. 2013.

KLOOGA, I.; HAIMB, A.; PORTNOVA, B.A. Using kernel density function as an urban analysis tool: investigating the association between nightlight exposure and the incidence of breast cancer in Haifa, Israel. Comput. Environ. Urban Syst., v.33, p.55-63, 2009.

LEISHMANIOSE visceral. [s.1.]: Secretaria de Vigilância em Saúde, 2013. Available in: $<$ http://portal.saude.gov.br $>$. Accessed in: 21 Jun. 2013.

LIMA-COSTA, M.F.; MATOS, D.L. LimaCosta \& Matos respondem. Cad. Saúde Publica, v.22, p.2497, 2006.

LOPES, E.G.P. Dinâmica da transmissão da leishmaniose visceral em uma coorte de cães em Juatuba, MG, de 2010 a 2011. 2013. 141f. Tese (Doutorado) - Escola de Veterinária, Universidade Federal de Minas Gerais, Belo Horizonte, MG.

LOPES, E.G.P.; MAGALHÃES, D.F.; SILVA, J.A. et al. Distribuição temporal e espacial da leishmaniose visceral em humanos e cães em Belo Horizonte, MG, 1993 a 2007. Arq. Bras. Med. Vet. Zootec., v.62, p.1062-1071, 2010.

LUTZ, A.; NEIVA, A. Contribuição para o conhecimento das espécies do gênero Phlebotomus existentes no Brasil. Mem. Inst. Oswaldo Cruz, v.4, p.84-95, 1912.

MANUAL de vigilância e controle da leishmaniose visceral. Brasília: Ministério da Saúde, 2014. 120p.

MINAS Gerais, Juatuba. [Rio de Janeiro]: IBGE, 2013. Available in: <http://www.ibge.gov.br/ cidadesat/xtras/perfil.php?codmun $=313665>$.

Accessed in: 19 Jun. 2013.
MORAIS, M.H.F.; MAGALHÃES, D.F.; ARAÚJO, V.E.M. et al. Sustentabilidade das ações de controle da leishmaniose visceral e as implicações da priorização de áreas de risco na expansão da doença no distrito sanitário noroeste de Belo Horizonte, Minas Gerais, 2006 a 2008. Rev. Soc. Bras. Med. Trop., v.41, p.77-81, 2008.

OLIVEIRA, C.L.; ASSUNÇÃO, R.M.; REIS, I.A. et al. Spatial distribution of human and canine visceral leishmaniasis in Belo Horizonte, Minas Gerais State, Brasil, 1994-1997. Cad. Saúde Pública, v.17, p.1231-1239, 2001.

PEREIRA, M.G. Epidemiologia teoria e prática. Rio de Janeiro: Guanabara Koogan, 2002. 595p.

PFEIFFER, D.U.; ROBINSON, T.; STEVENSON, M. et al. Spatial analysis in epidemiology. New York: University Press, 2009. 142p.

PRADO, P.F.; ROCHA, M.F.; SOUSA, J.F. et al. Epidemiological aspects of human and canine visceral leishmaniasis in Montes Claros, State of Minas Gerais, Brazil, between 2007 and 2009. Rev. Soc. Bras. Med. Trop., v.44, p.561-566, 2011.

ROMERO, G.A.S.; BOELAERT, M. Control of visceral leishmaniasis in Latin America: a systematic review. PLOS Neglected Trop. Dis., v.4, p.584, 2010.

RONDON, F.C.M.; BEVILACQUA, C.M.L.; FRANKE, C.R. et al. Cross-sectional serological study of canine leishmania infection in Fortaleza, Ceará state, Brazil. Vet. Parasitol., v.155, p.2431, 2008.

SILVA, E.S.; ROSCOE, E.H.; ARRUDA, L.Q. et al. Leishmaniose visceral canina: estudo clínico-epidemiológico e diagnóstico. Rev. Bras. Med. Vet., v.23, p.111-116, 2001.

WERNECK, G.L. Visceral leishmaniasis in Brazil: rationale and concerns related to reservoir control. Rev. Saúde Pública, v.48, p.851-855, 2014. 